\title{
Mitochondrial dysfunction induces aberrant insulin signalling and glucose utilisation in murine C2C12 myotube cells
}

Received: 17 January 2006 / Accepted: 18 February 2006 / Published online: 31 May 2006

C) Springer-Verlag 2006

\begin{abstract}
Aims/hypothesis: Mitochondrial dysfunction is considered a critical component in the development of diabetes. The aim of this study was to elucidate the molecular mechanisms involved in the development of insulin resistance and diabetes through investigation of mitochondrial retrograde signalling. Materials and methods: Mitochondrial function of $\mathrm{C} 2 \mathrm{C} 12$ myotube cells was impaired by genetic (ethidium bromide) and metabolic (oligomycin) stress, and changes in target molecules related to insulin signalling were analysed. Results: Concomitant with reductions in mitochondrial membrane potential $(\Delta \Psi \mathrm{m})$ and ATP synthesis, production of IRS1 and solute carrier family 2 (facilitated glucose transporter), member 4 (SLC2A4, formerly known as GLUT4) were reduced. Moreover, serine phosphorylation of IRS1 increased, resulting in decreased tyrosine phosphorylation. This indicates that mitochondrial dysfunction decreases insulin-stimulated SLC2A4 translocation and glucose uptake. Mitochondrial stress activated c-Jun N-terminal kinase (JNK) and p38 mitogen-activated protein kinase (p38 MAPK) signalling in a $\mathrm{Ca}^{2+}$-dependent manner, and removal of free $\mathrm{Ca}^{2+}$ by BAPTA-AM, as well as inhibition of JNK and p38 MAPK, abrogated mitochondrial stress-induced reductions in IRS1 and SLC2A4 production. Mitochondrial dysfunction after oligomycin treatment significantly increased levels of activating transcription factor 3 (ATF3), which represses Irs 1 promoter activity. Removal of the $5^{\prime}$ flanking region of Irs 1 demonstrated that the promoter region within 191 bases from the transcription site may be involved in the transcriptional repression of Irs 1 by mitochondrial stress.
\end{abstract}

\footnotetext{
J. H. Lim · J. I. Lee · Y. H. Suh · W. Kim •

J. H. Song $\cdot$ M. H. Jung $(\bowtie)$

Division of Metabolic Disease,

Department of Biomedical Science,

National Institute of Health,

5 Nokbun-dong, Eunpyung-gu,

Seoul 122-701, South Korea

e-mail: jung0603@nih.go.kr

Tel.: +82-2-3801530

Fax: +82-2-354-1057
}

Conclusions/interpretation: We show distinct mitochondrial retrograde signalling, where Irs 1 is downregulated through ATF3 in a $\mathrm{Ca}^{2+}$-, JNK- and p38 MAPK-dependent manner, and IRS1 is inactivated. Therefore, mitochondrial dysfunction causes aberrant insulin signalling and abnormal utilisation of glucose, as observed in many insulin resistance states.

Keywords Insulin resistance - Insulin signalling • Mitochondrial dysfunction $\cdot$ Retrograde signalling

Abbreviations ATF3: activating transcription factor 3 . BAPTA-AM: 1,2-bis( $o$-aminophenoxy)ethane- $N, N, N^{\prime}$, $N^{\prime}$-tetraacetic acid, tetraacetoxymethyl ester $\cdot \mathrm{CaMK}$ : calcium/calmodulin-dependent serine/threonine protein kinase - CREB: cAMP response element-binding - EtBr: ethidium bromide - GFP: green fluorescent protein - JNK: c-Jun N-terminal kinase - mtDNA: mitochondrial DNA · PKC: protein kinase C $\cdot$ p38 MAPK: p38 mitogenactivated protein kinase - SLC2A4: solute carrier family 2 (facilitated glucose transporter), member 4

\section{Introduction}

The cluster of pathologies known as the metabolic syndrome, including obesity, insulin resistance and type 2 diabetes, has become one of the most serious threats to human health. However, the molecular mechanisms underlying these individual disorders and their links with each other have not yet been elucidated. A number of studies have suggested that prominent features of type 2 diabetes are attributable to dysfunctional mitochondria [1-3]. Mutations in mitochondrial DNA (mtDNA) are associated with various disease states [4-7], a few of which are strongly associated with diabetes, including the A3243G mutation in the mitochondrial DNA-encoded $m t$-Tl1 [810]. In addition, maternally inherited defects in mtDNA that disrupt mitochondrial functioning are known to cause an insulin-deficient form of diabetes resembling type 1 diabetes [11]. Studies using the proton magnetic resonance 
spectroscopy technique have shown decreased mitochondrial activity and increased intramyocellular fat content in insulin-resistant children of parents with type 2 diabetes, a group with a strong tendency to develop diabetes later in life [12].

It has been shown that mitochondrial dysfunction can greatly modify nuclear gene expression [13]. Retrograde regulation, a general term for mitochondrial signalling, is broadly defined as cellular responses to changes in the functional status of mitochondria [14, 15]. Much of our understanding of the regulation of the retrograde response has been derived from studies with Saccharomyces cerevisiae [16-18]. In mammalian systems, mitochondrial retrograde signalling has been described in $\mathrm{C} 2 \mathrm{C} 12$ skeletal myoblasts and in human lung carcinoma A549 cells [19, 20]. Mitochondrial dysfunction in both cell types resulted in elevated cytosolic free $\mathrm{Ca}^{2+}$ and enhanced expression of genes involved in $\mathrm{Ca}^{2+}$ transport and storage, including ryanodine receptors I and II [14, 19]. Furthermore, increased $\mathrm{Ca}^{2+}$ correlated with activation of several $\mathrm{Ca}^{2+}$ dependent protein kinases, including protein kinase $\mathrm{C}$ (PKC) and calcium/calmodulin-dependent serine/threonine protein kinase $(\mathrm{CaMK})[21,22]$, and $\mathrm{Ca}^{2+}$-responsive transcription factors [19].

Activating transcription factor 3 (ATF3) is a member of the ATF/cAMP-response element-binding (CREB) protein family of transcription factors, which recognise a consensus DNA sequence, TGACGTCA, and have structurally similar basic region/leucine zipper domains. They interact selectively with each other to form hetero- or homodimers through their leucine zipper regions [23]. Despite overwhelming evidence indicating that $A T F 3$ is a stressinducible gene in a variety of tissues and acts as a transcriptional repressor, the physiological consequences of Atf 3 expression are not well understood. However, it was recently reported that $A t f 3$ is expressed in primary sensory neurons of diabetic mice [24] and ATF3 is expressed in the islets of patients with type 1 or type 2 diabetes $[25,26]$.

Here, we investigate the effects of mitochondrial dysfunction on the development of insulin resistance in C2C12 myotube cells with functionally inactive mitochondria. Our findings show that mitochondrial dysfunction represses IRS1 through ATF3 in a $\mathrm{Ca}^{2+}$ - and c-Jun $\mathrm{N}$-terminal kinase (JNK)-dependent manner. Additionally, inactivation of IRS1 by increased serine phosphorylation and decreased tyrosine phosphorylation results in the aberrant insulin signalling and abnormal glucose utilisation observed in many insulin resistance states.

\section{Materials and methods}

Materials

Oligomycin and the somatic cell ATP assay kit were purchased from Sigma (St Louis, MO, USA). The kinase inhibitors SP600125, SB203580, Calphostin C and KN-93 were from Calbiochem (San Diego, CA, USA), and 1,2-bis (o-aminophenoxy)ethane- $N, N, N^{\prime}, N^{\prime}$-tetraacetic acid, tetraacetoxymethyl ester (BAPTA-AM) was obtained from Molecular Probes (Eugene, OR, USA).

Induction of mitochondrial dysfunction

Murine C2C12 skeletal myoblast cells (ATCC CRL 1772; American Type Culture Collection, Manassas, VA, USA) were grown in DMEM supplemented with $2 \%$ horse serum to induce differentiation into myotubes. Cells with functionally inactivated mitochondria were obtained by growing $\mathrm{C} 2 \mathrm{C} 12$ cells in serum-supplemented DMEM containing $1 \mathrm{mmol} / \mathrm{l}$ pyruvate, $50 \mu \mathrm{g} / \mathrm{ml}$ uridine and 200 or $500 \mathrm{ng} / \mathrm{ml}$ ethidium bromide (EtBr) for 4 weeks to selectively inhibit mtDNA replication and transcription without detectable effects on the nuclear DNA $[19,20]$. To disturb mitochondrial electron transport, differentiated $\mathrm{C} 2 \mathrm{C} 12$ myotubes were treated with 20 or $40 \mu \mathrm{mol} / 1$ oligomycin, an inhibitor of mitochondrial ATPase, for $24 \mathrm{~h}$.

To reverse mitochondrial dysfunction, cells were grown for at least 1 (oligomycin-treated) or 7 (EtBr-treated) days after removal of either oligomycin or $\mathrm{EtBr}$ from media.

Measurement of mitochondrial membrane potential $(\Delta \Psi \mathrm{m})$ and cellular calcium concentration

Mitochondrial membrane potential was determined using MitoTracker, a mitochondrially selective probe. Oligomycin- or EtBr-treated and untreated $\mathrm{C} 2 \mathrm{C} 12$ cells in serumfree medium were incubated with $100 \mathrm{nmol} / \mathrm{l}$ MitoTracker Green FM (Molecular Probes) for $30 \mathrm{~min}$, and fluorescent signals were detected using a confocal microscope (Radiance 2000; Bio-Rad, Hercules, CA, USA) at $490 / 516 \mathrm{~nm}$ (excitation/emission).

Cellular steady-state $\mathrm{Ca}^{2+}$ levels were measured by confocal microscopy (Bio-Rad) at 494/516 nm (excitation/ emission) using Fluo-4 AM (Molecular Probes) loaded into $\mathrm{C} 2 \mathrm{C} 12$ cells to a final concentration of $5 \mu \mathrm{mol} / 1$ for $1 \mathrm{~h}$.

\section{Western blot analysis}

The cell lysates were subjected to electrophoresis through 10\% SDS-PAGE and blotted with antibodies for IRS1, solute carrier family 2 (facilitated glucose transporter), member 4 (SLC2A4, formerly known as GLUT4) and $\beta$-actin purchased from Santa Cruz Biotechnology (Santa Cruz, CA, USA), and phospho-IRS1, JNK, phospho-JNK, p38 mitogen-activated protein kinase (p38 MAPK) and phospho-p38 MAPK purchased from Cell Signaling Technology (Beverly, MA, USA). The immunoblots were visualised by chemiluminescence using the ECL Western Blotting System (Amersham Biosciences, Freiburg, Germany). 
Determination of IRS1 tyrosine phosphorylation by immunoprecipitation

Endogenous IRS1 (1 mg) was immunoprecipitated with $10 \mu \mathrm{g}$ of anti-IRS1 antibody (Santa Cruz Biotechnology) from the lysates of control or oligomycin-treated $(40 \mu \mathrm{mol} /$ 1) cells for $24 \mathrm{~h}$. Immune complexes were immobilised by the addition of $30 \mu \mathrm{l}$ of protein A-Sepharose (Amersham Biosciences) and then eluted by the addition of $40 \mu \mathrm{l}$ sample buffer. The amounts of tyrosine-phosphorylated and total IRS1 were determined by Western blotting using specific phosphotyrosine (Cell Signaling Technology) and IRS1 (Santa Cruz Biotechnology) antibodies respectively.

Measurement of triglyceride accumulation

Cells were completely lysed at $4^{\circ} \mathrm{C}$ using ultrasonication (Sonics \& Materials, Newtown, CT, USA). After centrifugation at 3,500 rpm for $5 \mathrm{~min}$, the supernatant was used for measurement of triglyceride. The amount of triglyceride was quantitated colorimetrically as glycerol using an enzymatic assay kit (Asan Pharm, Seoul, South Korea).

\section{Determination of SLC2A4-GFP translocation}

Control pGFP vectors were generated by removing Slc $2 a 4$ cDNA sequences from pSLC2A4-GFP at the EcoRI and NotI sites, followed by DNA PolI (Klenow fragment)mediated filling and blunt-end ligation. Each construct was transiently transfected into $\mathrm{C} 2 \mathrm{C} 12$ myotubes using Lipofectamine 2000 Transfection Reagent (Invitrogen, Karlsruhe, Germany). Cells were treated with $40 \mu \mathrm{mol} / 1$ oligomycin for $24 \mathrm{~h}$ to induce mitochondrial dysfunction, starved for $20 \mathrm{~h}$, and then fixed as single cells for examination under confocal microscopy. The time at which insulin $(100 \mathrm{nmol} / \mathrm{l})$ was applied to the cells was set to zero, and the movements of SLC2A4-GFP or green fluorescent protein (GFP) were chased over time.

\section{Measurement of 2-deoxy-[ $\left.{ }^{3} \mathrm{H}\right]$-D-glucose uptake}

After induction of mitochondrial dysfunction, cells were starved for $24 \mathrm{~h}$ and washed twice with HEPES buffer (20 mmol/1 HEPES [pH 7.4], $140 \mathrm{mmol} / 1 \mathrm{NaCl}, 2.5 \mathrm{mmol} / 1$ $\mathrm{MgSO}_{4}, 5 \mathrm{mmol} / \mathrm{l} \mathrm{KCl}, 1 \mathrm{mmol} / \mathrm{CaCl}_{2}$ ). Cells were preincubated with HEPES buffer for $1 \mathrm{~h}$ and incubated for $10 \mathrm{~min}$ in the presence or absence of $100 \mathrm{nmol} / \mathrm{l}$ insulin, followed by treatment with 2-deoxy- $\left[{ }^{3} \mathrm{H}\right]$-D-glucose $(37,000 \mathrm{~Bq} / \mathrm{ml}$; Amersham Biosciences) for $10 \mathrm{~min}$. The uptake was stopped by adding $10 \mu \mathrm{mol} / \mathrm{l}$ cytochalasin B. After washing with ice-cold $0.9 \% \mathrm{NaCl}$ three times, total cells were lysed with $0.1 \mathrm{~mol} / 1 \mathrm{NaOH}$. Non-specific uptake was measured in the presence of $10 \mu \mathrm{mol} / 1$ cytochalasin B and was subtracted from all the values.
Luciferase assay

Using the internal pBlue-IRS1 restriction enzymes KpnI and XhoI, we generated the Irs 1 promoter, pGL3-IRS1 L $(2,535 \mathrm{bp})$, with the pGL3 basic vector (Promega, Madison, WI, USA). To generate the deletion construct, pGL3-IRS1 S, an internal region of 2,084 bp from the EcoRV and SmaI fragment was removed from the pGL3IRS1 L. Cells were transfected using the Lipofectamine 2000 Transfection Reagent (Invitrogen), and luciferase activities were measured with the luciferase assay system (Promega) according to the manufacturer's instructions. The pcDNA3.1- $\beta$-galactosidase (pcDNA3.1-LacZ) expression vector (Invitrogen) was used as an internal control to normalise firefly luciferase activity. In certain experiments, cells were treated for 30 min with BAPTA-AM $(20 \mu \mathrm{mol} / \mathrm{l})$ prior to oligomycin $(40 \mu \mathrm{mol} / \mathrm{l})$ treatment for $24 \mathrm{~h}$.

\section{Statistical analysis}

All the data are expressed as means \pm SEM. Differences between the groups were determined by one-way analysis of variance (ANOVA) using the SAS statistical analysis program (SAS Institute, Cary, NC, USA). Results were considered significant if the value of $p$ was less than 0.05 . Duncan's multiple range test was performed to evaluate any differences between the groups.

\section{Results}

Mitochondrial dysfunction represses IRS1 and SLC2A4

The degree of mitochondrial dysfunction induced by metabolic (oligomycin) and genetic (EtBr) stress was measured in two different $\mathrm{C} 2 \mathrm{C} 12$ model systems. As $\mathrm{C} 2 \mathrm{C} 12$ myoblast cells lose their ability to differentiate into myotubes and develop invasive phenotypes after treatment with $\mathrm{EtBr}$ or metabolic inhibitors [20, 27], the myoblast cells were allowed to differentiate into myotubes prior to induction of mitochondrial dysfunction. In both oligomycin-treated and EtBr-treated $\mathrm{C} 2 \mathrm{C} 12$ cells, the change in mitochondrial membrane potential $(\Delta \Psi \mathrm{m})$ was dramatically reduced (Fig. 1a). In contrast, mtDNA content decreased only slightly after treatment with as much as $500 \mathrm{ng} / \mathrm{ml} \mathrm{EtBr}$ (data not shown). As expected with decreased $\Delta \Psi \mathrm{m}$, total cellular ATP from oligomycin- and EtBr-treated $\mathrm{C} 2 \mathrm{C} 12$ cells were substantially reduced compared with control cells (Fig. 1b). These results confirm that treatment with either oligomycin or $\mathrm{EtBr}$ impairs mitochondrial functioning in $\mathrm{C} 2 \mathrm{C} 12$ myotubes. To determine whether $\mathrm{EtBr}$ or oligomycin treatment caused cytotoxicity of $\mathrm{C} 2 \mathrm{C} 12$ myotube cells, we examined cell viability by the MTT (3-[4,5-dimethylthiazol-2-yl]-2,5diphenyl tetrazolium bromide) assay after induction of mitochondrial dysfunction. Figure 1c shows that mito- 
chondrial dysfunction did not result in changes in the cellular viability of $\mathrm{C} 2 \mathrm{C} 12$ cells.

As defective insulin signalling is believed primarily to lead to insulin resistance [28, 29], the expression of specific molecules involved in insulin signalling and glucose transport was examined in $\mathrm{C} 2 \mathrm{C} 12$ cells with dysfunctional mitochondria. Our findings show that the production of IRS1 and SLC2A4 declined drastically after treatment with oligomycin or EtBr (Fig. 2a, b). In contrast, the production of phosphoinositide-3 kinase (PI3K) and Akt (a downstream serine/threonine kinase of IRS1) was unaffected by mitochondrial dysfunction (Fig. 2c). Production of IRS1 and SLC2A4 returned to almost control levels when C2C12 myotube cells were grown in media without oligomycin or EtBr (Fig. 2a, b), suggesting that changes in IRS1 and SLC2A4 production are due mainly to mitochondrial dysfunction.
Fig. 1 Induction of mitochondrial dysfunction in $\mathrm{C} 2 \mathrm{C} 12$ myotube cells. a Changes in mitochondrial membrane potential in $\mathrm{C} 2 \mathrm{C} 12$ cells containing functionally inactive mitochondria. Cells stained with 100 nmol/1 MitoTracker Green FM were visualised by confocal microscopy. b Cellular ATP content was measured based on ATP-driven luciferin luciferase activity [19]. The ATP content from control $\mathrm{C} 2 \mathrm{C} 12$ cells was set to $100 \%$ and ATP contents of oligomycin- or EtBr-treated cells are indicated as percentages of control. c Determination of cell viability. Cell viability was measured either in control or oligomycin-treated cells using 3-[4,5-dimethylthiazol2-yl]-2,5-diphenyl tetrazolium bromide (MTT) as a substrate. All values are means \pm SEM from four independent experiments. $* * p<0.001$ for pairwise comparisons (ANOVA: b $p<0.0001$; c not significant)
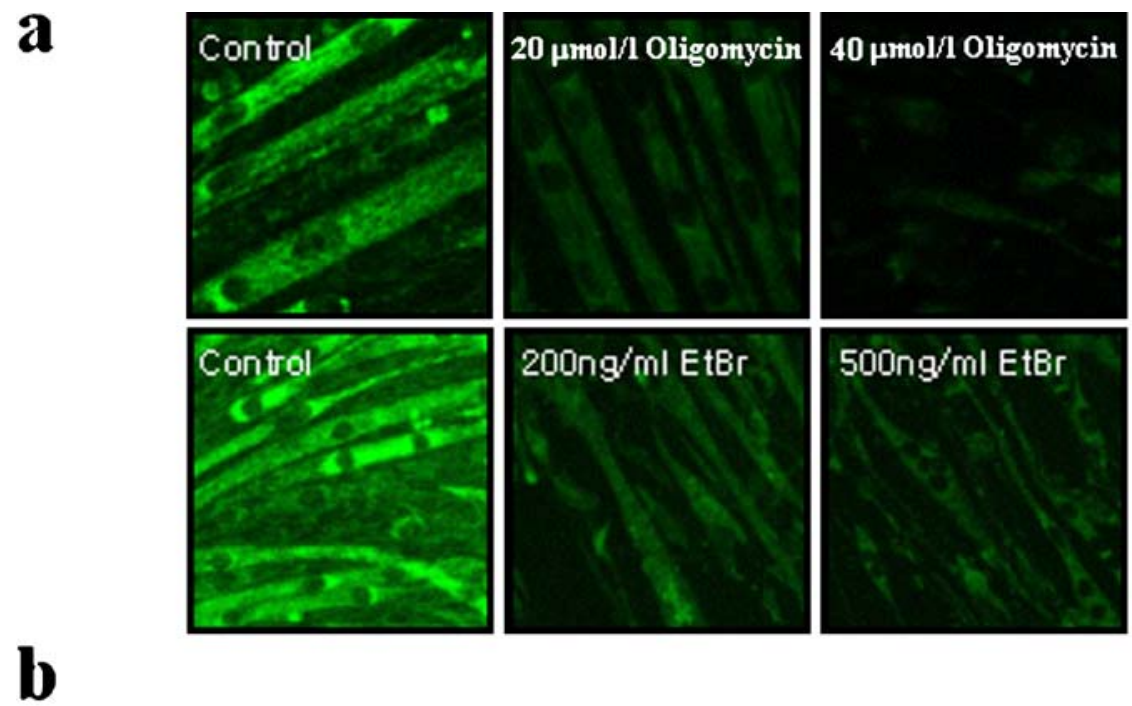

b
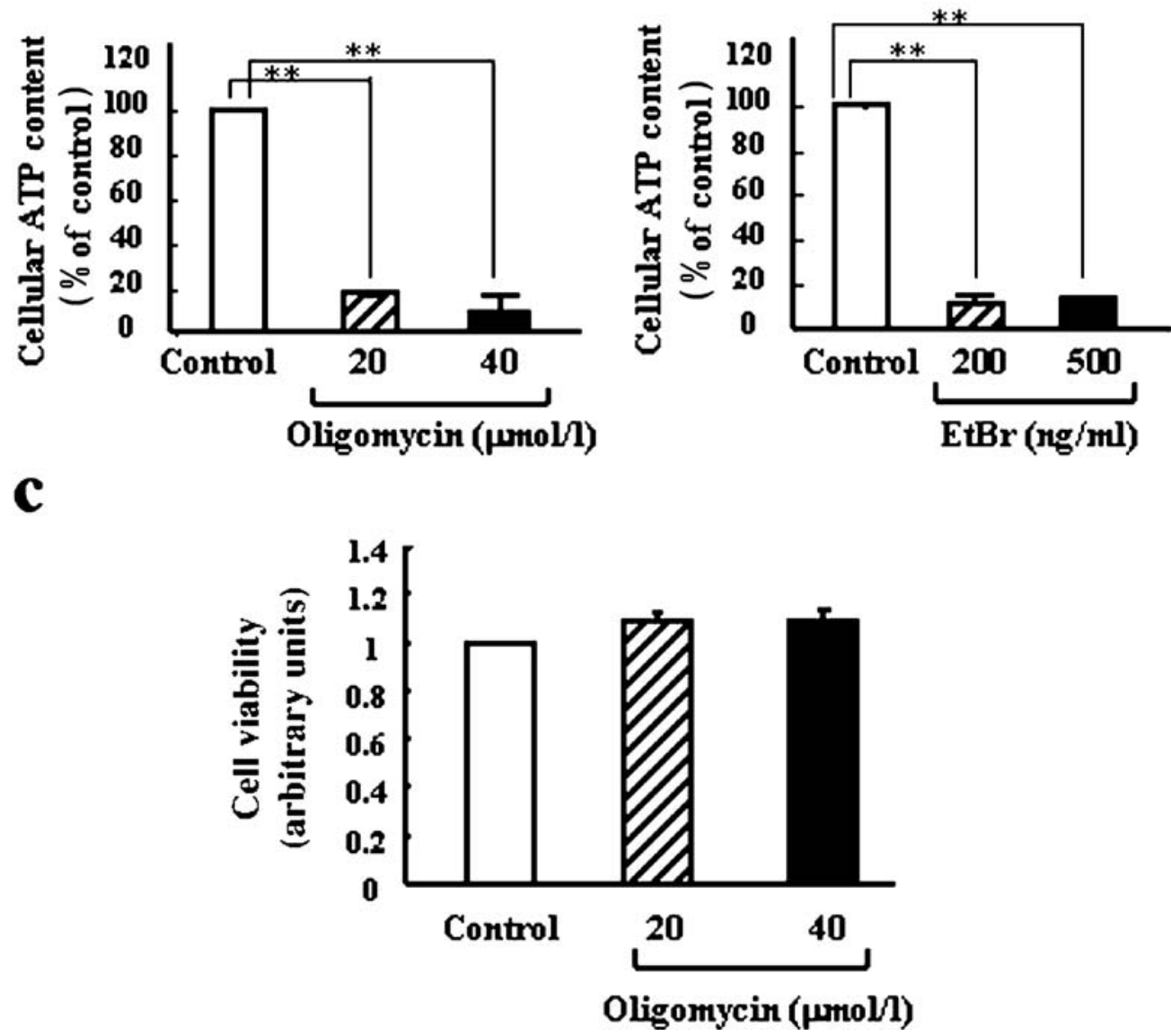
Fig. 2 Mitochondrial dysfunction reduces production of IRS1 and SLC2A4. Mitochondrial dysfunction was induced by either 20 or $40 \mu \mathrm{mol} / 1$ oligomycin (a) or by long-term treatment with 200 or $500 \mathrm{ng} / \mathrm{ml}$ $\mathrm{EtBr}(\mathbf{b})$, and production of IRS1 or SLC2A4 was determined by Western blot analysis. c PI3K and Akt production in oligomycin- or EtBr-treated C2C12 cells analysed by Western blot analysis. Protein levels obtained by densitometry were normalised against $\beta$-actin signals. The intensity of the control was set to $100 \%$. All results are expressed as means \pm SEM from more than three independent experiments. $* * p<0.001$ for pairwise comparisons (ANOVA: a $p<0.0001$; b $p<0.0002)$. Rev., lysate obtained from cells containing reversion of mitochondrial dysfunction a

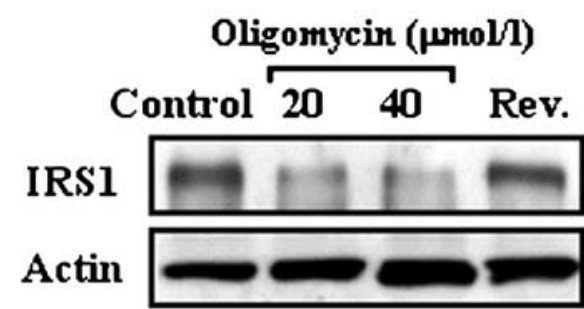

b
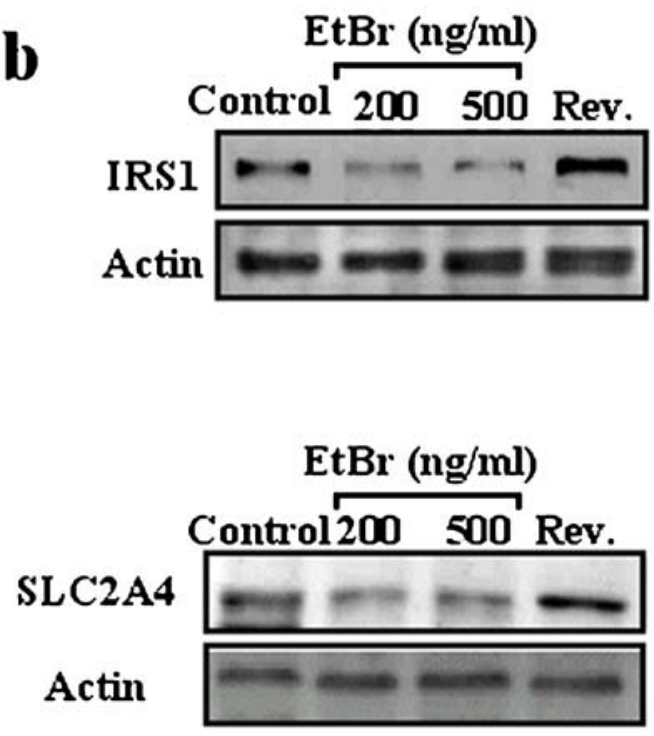

Oligomycin (

C

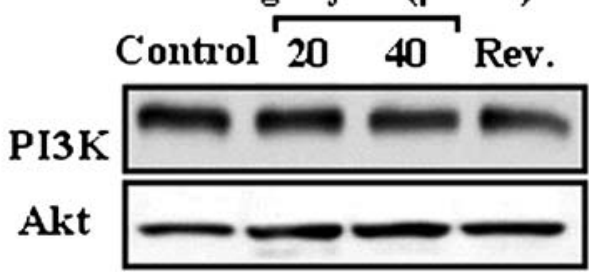

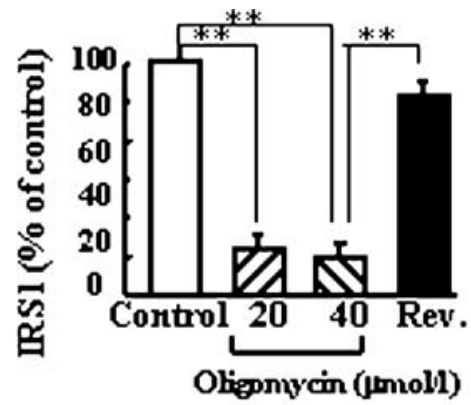
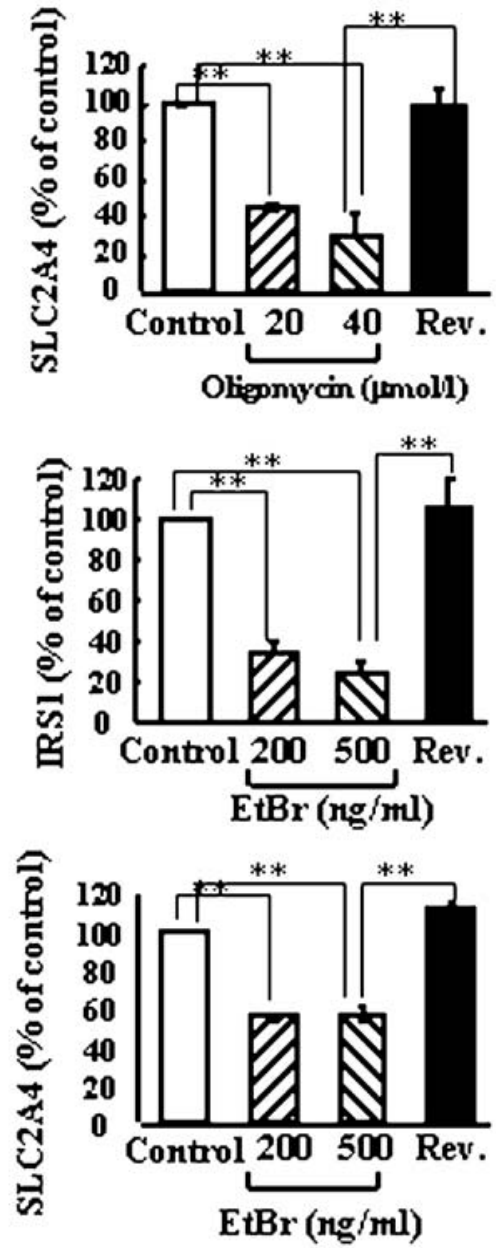

$\operatorname{EtBr}(\mathrm{ng} / \mathrm{ml})$

Control 200500 Rev.

PI3K

Akt
Mitochondrial dysfunction increases IRS1 serine phosphorylation and attenuates insulin-stimulated tyrosine phosphorylation

There is growing evidence that increased IRS1 serine phosphorylation blocks the tyrosine phosphorylation evoked by the insulin receptor, thereby inhibiting the insulin signalling pathway [30-32]. We examined serine phosphorylation and insulin-stimulated tyrosine phosphorylation of IRS1 in $\mathrm{C} 2 \mathrm{C} 12$ cells whose mitochondria were dysfunctional. As shown in Fig. 3a, although IRS1 production decreased, phosphorylation of Ser307, a JNKspecific phosphorylation site, and Ser636/639, a mammalian target of rapamycin (mTOR)-specific phosphorylation 
site, increased greatly in both oligomycin- and EtBr-treated $\mathrm{C} 2 \mathrm{C} 12$ cells. When reductions in IRS1 protein abundance were compensated, the serine phosphorylation of IRS1 increased greater than four-fold compared with control levels, in oligomycin or EtBr-treated C2C12 cells (Fig. 3b). To determine whether reduced IRS1 production and increased serine phosphorylation affect insulin-stimulated tyrosine phosphorylation of IRS1, the level of tyrosinephosphorylated IRS1 was measured after immunoprecipitation with IRS1 antibodies. Immunoprecipitated IRS1 $(1 \mathrm{mg})$ was electrophoresed and the presence of tyrosinephosphorylated IRS1 was determined by blotting with antiphosphotyrosine antibody. Results show that insulinstimulated tyrosine phosphorylation of IRS1 increased in normal cells, but was absent in oligomycin-treated cells (Fig. 3c). Insulin-stimulated phosphorylation of Akt, a downstream serine/threonine kinase of IRS1, was also nearly abolished by oligomycin treatment (Fig. 3d). These results show that mitochondrial dysfunction also impairs insulin signalling by increasing serine phosphorylation of IRS1, resulting in significant reduction in insulin-stimulated tyrosine phosphorylation.

Because it has been reported that mitochondrial dysfunction increases intramyocellular lipid metabolites, which may activate serine/threonine kinases and repress insulin signalling by phosphorylating IRS1 [12, 33-35], we probed for the presence of lipids in oligomycin-treated C2C12 cells. As shown in Fig. 4, triglycerides accumulated
Fig. 3 Mitochondrial dysfunction impairs insulin signalling. a Inactivation of IRS1 by increased serine phosphorylation in both oligomycin- and $\mathrm{EtBr}$ treated $\mathrm{C} 2 \mathrm{C} 12$ cells. Western blot analysis was performed as described in Materials and methods using the antibodies indicated. b Levels of serine phosphorylation compensated for loss of protein production. This is expressed here as relative values in arbitrary units, the intensity of serine phosphorylation/whole IRS1 for control cells being set to 1 . Results are expressed as means \pm SEM for $n=3$ (ANOVA: $* p<0.081$; $* * p<0.0001)$. Empty bars, Ser307; filled bars, Ser636/639. c Tyrosine phosphorylation of IRS1 protein was determined by Western blot analysis using phosphotyrosine antibody after immunoprecipitation with IRS1 antibody as described in Materials and methods. d The production and phosphorylation level of Akt were determined by Western blot analysis with specific antibodies recognising whole Akt and phospho-Akt (Ser473), respectively $\mathbf{a}$

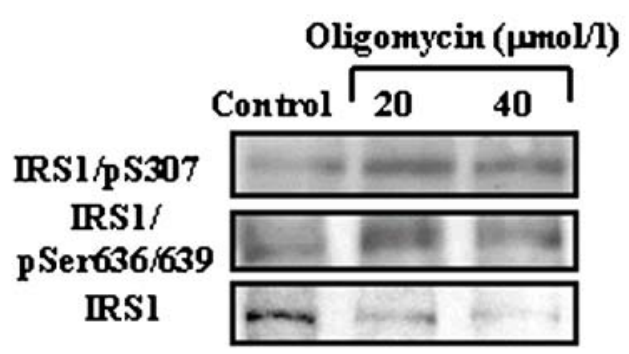

b

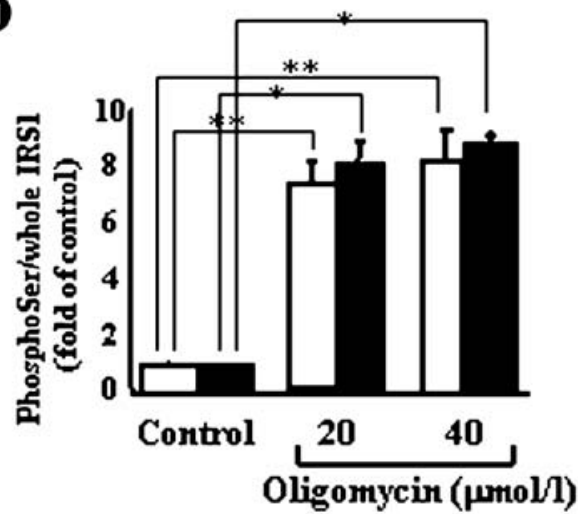

$\mathrm{EtBr}(\mathrm{ng} / \mathrm{ml})$
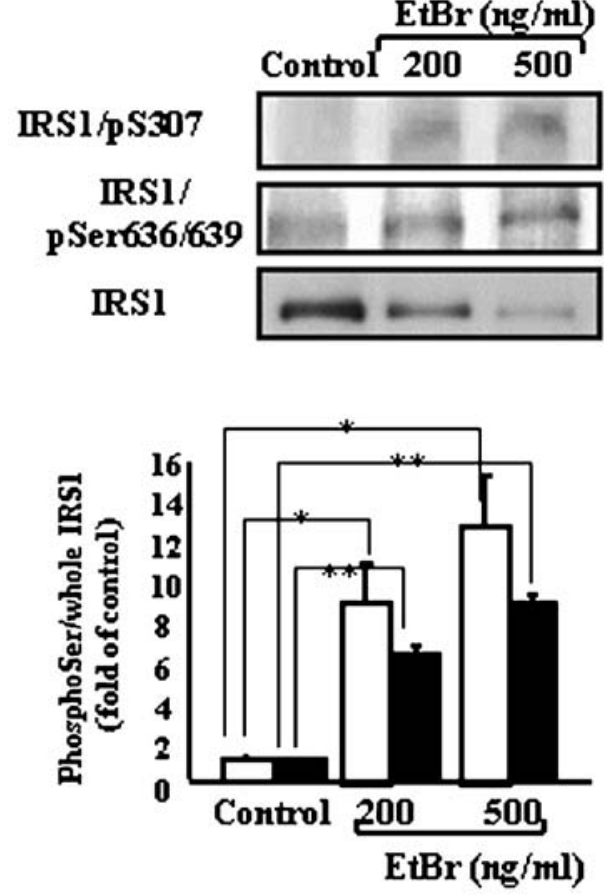

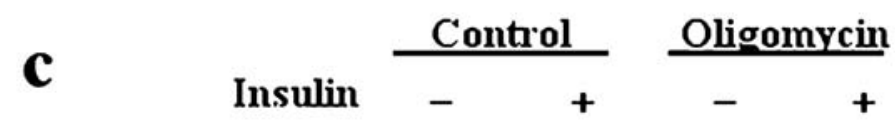

Phospho-Tyr

IRS1
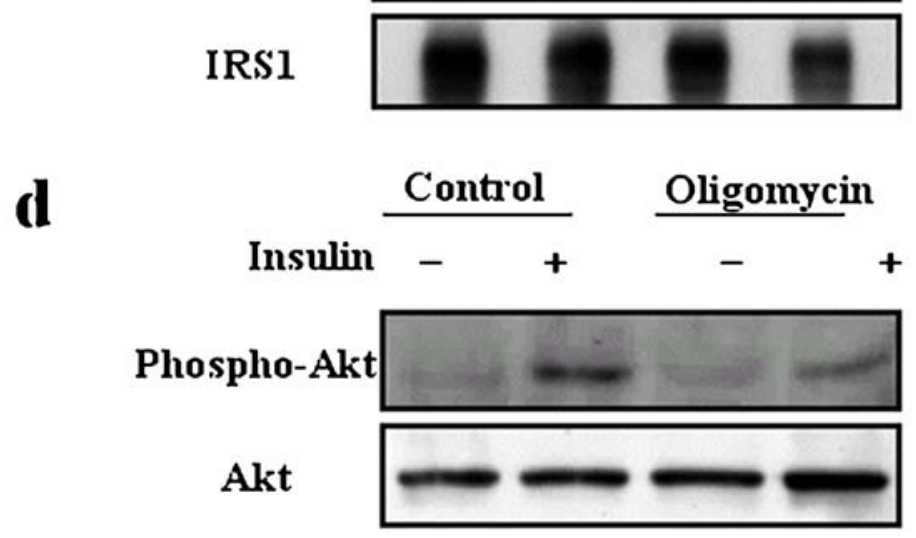
more than two-fold after treatment with $40 \mu \mathrm{mol} / 1$ oligomycin, suggesting that elevated levels of lipid metabolites may also be involved in interfering with insulin signalling in $\mathrm{C} 2 \mathrm{C} 12$ cells containing dysfunctional mitochondria.

Mitochondrial dysfunction impairs glucose utilisation in $\mathrm{C} 2 \mathrm{C} 12$ myotubes

To elucidate whether the overall reduction in insulin signalling observed in cells with dysfunctional mitochondria causes abnormal utilisation of glucose, we examined the translocation of SLC2A4 to plasma membrane and glucose uptake in oligomycin-treated $\mathrm{C} 2 \mathrm{C} 12$ myotubes. Translocation of SLC2A4 by insulin was measured under confocal microscopy after $\mathrm{C} 2 \mathrm{C} 12$ cells had been transfected with SLC2A4-GFP. Selecting a single cell from control or oligomycin-treated $\mathrm{C} 2 \mathrm{C} 12$ cells for examination, SLC2A4 movement was monitored every minute immediately after insulin treatment. When the GFP construct alone was transfected in $\mathrm{C} 2 \mathrm{C} 12$ cells, GFP proteins were dispersed throughout the whole cell and were unaffected by stimuli (Fig. 5a). However, most cells showed SLC2A4GFP proteins as transport vesicles that mainly clustered in intracellular storage sites around the nucleus. In control cells untreated with oligomycin, SLC2A4-GFP proteins were constantly recycled. Net translocation of the SLC2A4-GFP proteins into the plasma membrane occurred within 30 min after insulin stimulation, reflecting greater fluorescence on the cell surface (Fig. 5a). In contrast, no remarkable movement of SLC2A4-GFP proteins was observed in oligomycin-treated $\mathrm{C} 2 \mathrm{C} 12$ cells, most of the SLC2A4-GFP proteins being sequestered within intracel-

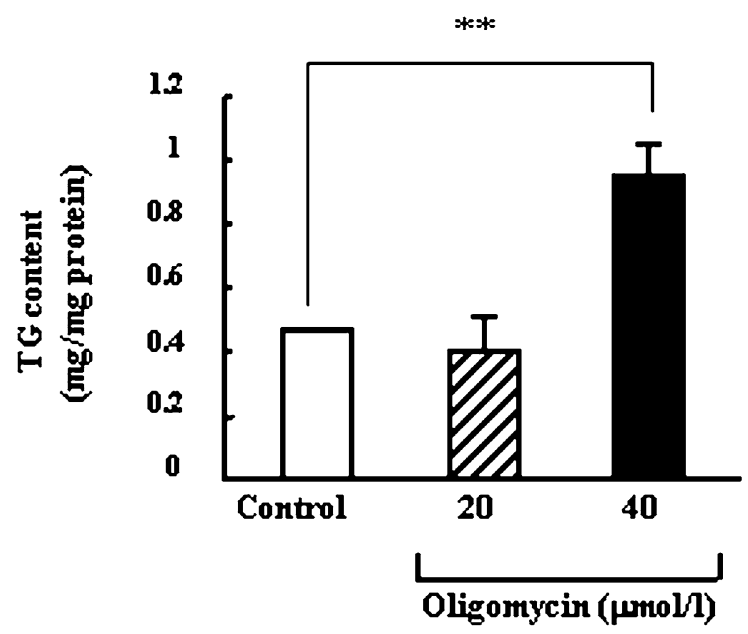

Fig. 4 Mitochondrial dysfunction increased triglyceride (TG) accumulation in $\mathrm{C} 2 \mathrm{C} 12$ myotube cells. Triglyceride accumulation was quantitated colorimetrically as described in Materials and methods. Values are means \pm SEM from three independent experiments. ${ }^{* *} p<0.001$ for pairwise comparisons (ANOVA: $p=0.0006$ )
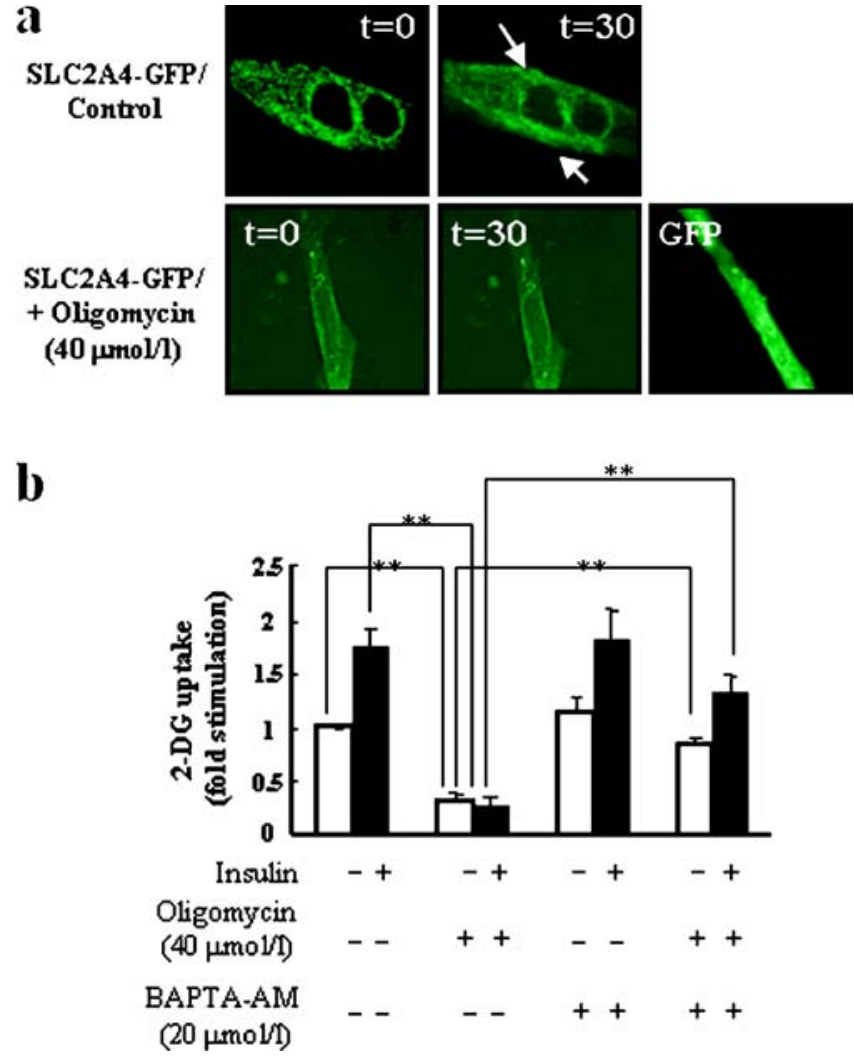

Fig. 5 Reduction of glucose uptake under conditions of mitochondrial dysfunction. a Insulin-dependent translocation of SLC2A4 to the plasma membrane was measured by confocal microscopy as described in Materials and methods. b After treatment with $100 \mathrm{nmol} / 1$ insulin for $10 \mathrm{~min}$ as indicated, 2-deoxy-[ $\left.{ }^{3} \mathrm{H}\right]$-D-glucose (2-DG) uptake was measured as described in Materials and methods. All values are means \pm SEM from five independent experiments. $* * p<0.001$ for pairwise comparisons (ANOVA: $p=0.0001$ )

lular storage sites during the entire period of insulin treatment (Fig. 5a). This indicates that mitochondrial dysfunction may interfere with SLC2A4 recycling and translocation.

Next, the effects of mitochondrial dysfunction on glucose uptake were investigated. As Fig. 5b reveals, basal glucose uptake was significantly reduced, by about $60 \%$, in oligomycin-treated $\mathrm{C} 2 \mathrm{C} 12$ cells compared with control cells. Moreover, there was no insulin stimulatedglucose uptake in oligomycin-treated $\mathrm{C} 2 \mathrm{C} 12$ cells, whereas insulin-stimulated glucose uptake increased 1.8-fold in control cells. The decreased glucose uptake in oligomycintreated $\mathrm{C} 2 \mathrm{C} 12$ cells may have resulted from both reduced SLC2A4 content and translocation potential together with impaired insulin signalling. Interestingly, when $\mathrm{C} 2 \mathrm{C} 12$ cells were pretreated with BAPTA-AM, the basal glucose uptake was restored to $90 \%$ of normal, and insulinstimulated glucose uptake also recovered. From these results, it was postulated that a $\mathrm{Ca}^{2+}$-dependent signalling pathway may be involved in the abnormal glucose utilisation and aberrant insulin signalling induced by mitochondrial dysfunction. 
Elevated cytosolic $\mathrm{Ca}^{2+}$ and activation of JNK and p38 MAPK induced by mitochondrial dysfunction repress IRS1

Mitochondrial signalling leading to reduced IRS1 and SLC2A4 production was further characterised with regard to the possible involvement of $\mathrm{Ca}^{2+}$-dependent signalling.
First, levels of cellular free $\mathrm{Ca}^{2+}$ were measured in $\mathrm{C} 2 \mathrm{C} 12$ myotubes with dysfunctional mitochondria. As shown in Fig. 6a, steady-state $\mathrm{Ca}^{2+}$ levels increased dramatically in both oligomycin- and EtBr-treated cells. However, in cells pretreated with BAPTA-AM $(20 \mu \mathrm{mol} / \mathrm{l})$, elevated $\mathrm{Ca}^{2+}$ levels were reduced to control levels. The role of elevated cellular steady-state $\mathrm{Ca}^{2+}$ in reducing IRS1 production was
Fig. 6 Aberrant steady-state $\mathrm{Ca}^{2+}$ level and activation of protein kinases downregulate IRS1 in oligomycin- and EtBrtreated $\mathrm{C} 2 \mathrm{C} 12$ cells. a Steadystate $\mathrm{Ca}^{2+}$ levels were measured in Fluo-4-loaded C2C12 cells as described in Materials and methods. b-d Recovery of IRS1 production by BAPTA-AM and $\mathrm{Ca}^{2+}$-dependent protein kinase inhibitors. Cells were pretreated for $30 \mathrm{~min}$ with BAPTA-AM $(20 \mu \mathrm{mol} / \mathrm{l}), \mathrm{SB} 203580$

$(5 \mu \mathrm{mol} / 1)$, SP600125 $(20 \mu \mathrm{mol} / \mathrm{l})$, Calphostin C $(1 \mu \mathrm{mol} / \mathrm{l})$ or $\mathrm{KN}-93(50 \mu \mathrm{mol} / \mathrm{l})$. After induction of mitochondrial dysfunction with the addition of oligomycin $(40 \mu \mathrm{mol} / \mathrm{l})$ for $24 \mathrm{~h}$, cells were collected and subjected to Western blot analysis a
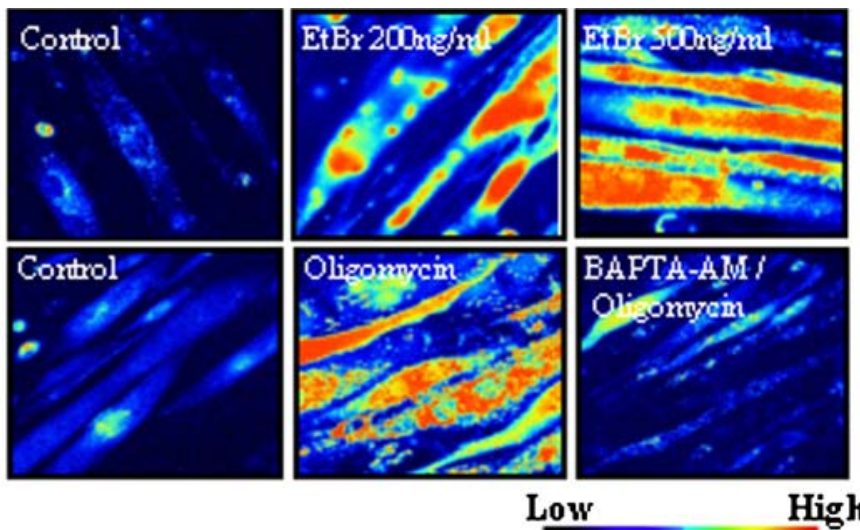

High

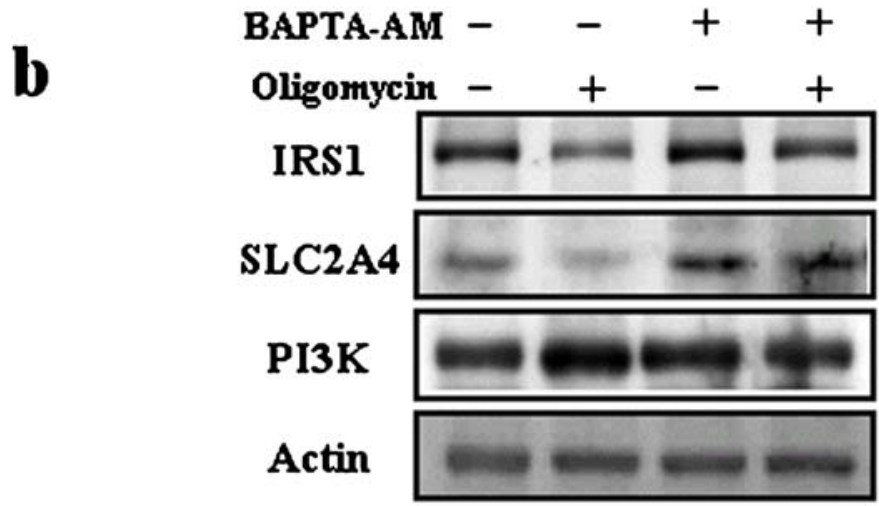

C

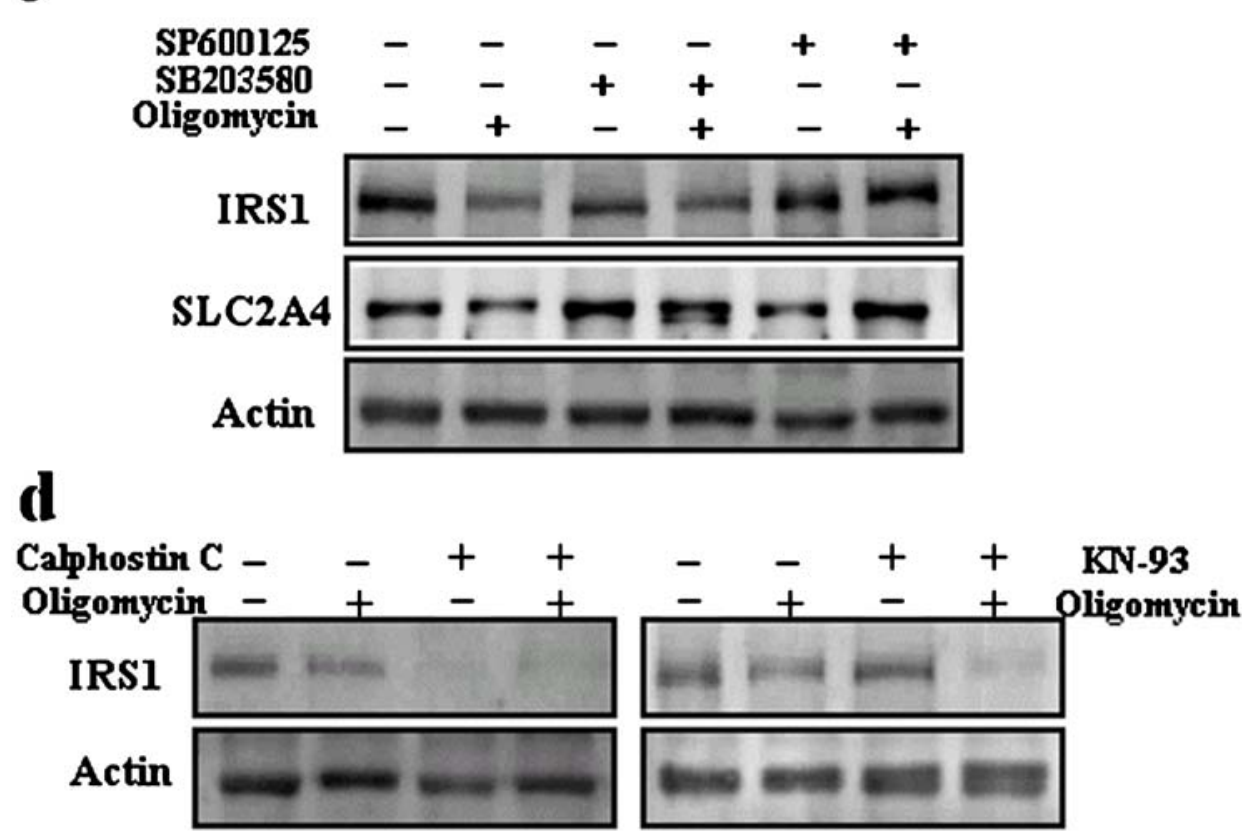


examined. In Fig. 6b, removal of free $\mathrm{Ca}^{2+}$ by BAPTA-AM abrogated the decreased IRS1 production, suggesting that reduced IRS1 production from mitochondrial dysfunction is mediated by $\mathrm{Ca}^{2+}$-dependent retrograde signalling.

Calcium can activate a number of protein kinases, including PKC, protein kinase A, CaMK and MAPK [21, $22,36,37]$. To gain further insight into the potential mechanism whereby IRS1 production is repressed by mitochondrial dysfunction, the effects of several protein kinase inhibitors on IRS1 production were examined. As shown in Fig. 6c, SP600125 and SB203580, inhibitors of JNK and p38 MAPK respectively, partially restored IRS1 production, indicating that JNK and p38 MAPK independently play a role in regulating IRS1 production. In contrast, Calphostin $\mathrm{C}$ and $\mathrm{KN}-93$, which are inhibitors of PKC and CaMK respectively, repressed IRS1 even further (Fig. 6d). To establish whether JNK and p38 MAPK are activated by mitochondrial dysfunction, we investigated phosphorylation of JNK and p38 MAPK in oligomycin- or EtBr-treated cells. As shown in Fig. 7a, basal phosphorylation of JNK and p38 MAPK increased more than threefold in both oligomycin- and EtBr-treated cells, although protein levels remained the same. In addition, pretreatment with BAPTA-AM effectively blocked the increases in JNK
Fig. 7 Phosphorylation of MAP kinases in $\mathrm{C} 2 \mathrm{C} 12$ cells containing functionally inactive mitochondria. a Total protein was subjected to $10 \%$ SDS-PAGE and immunoblotted with JNK, phospho-JNK (Thr183/Tyr185) (empty bars, p46; filled bars, p54), p38 MAPK or phosphop38 MAPK (Thr180/Tyr182). b Cells were pretreated for 30 min with BAPTA-AM $(20 \mu \mathrm{mol} / \mathrm{l})$ and phosphorylation of JNK and p38 MAPK was examined as described in a. Results are means \pm SEM for $n=3 .{ }^{*} p<0.01, * * p<0.001$ for pairwise comparisons (ANOVA: JNK, $p<0.0092$; p38MAPK, $p<0.0025$ ) $\mathbf{a}$

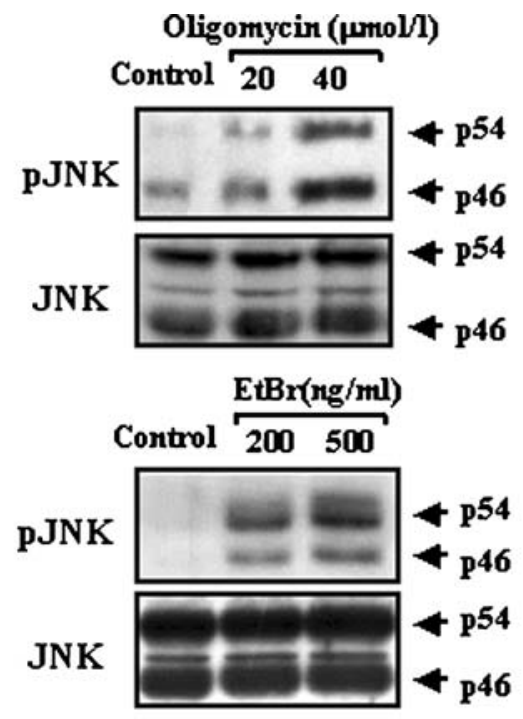

Oligomycin (

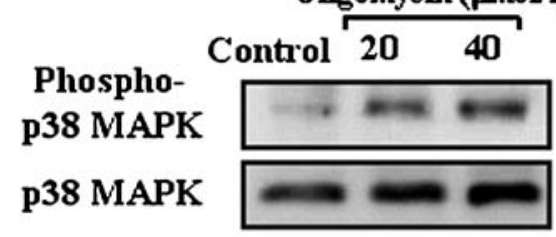

$\operatorname{EtBr}(\mathbf{n g} / \mathrm{ml})$

Control $200 \mathbf{5 0 0}$

Phosphop38 MAPK p38 MAPK

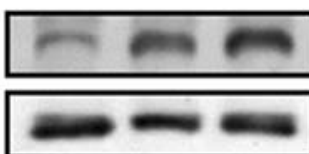

b

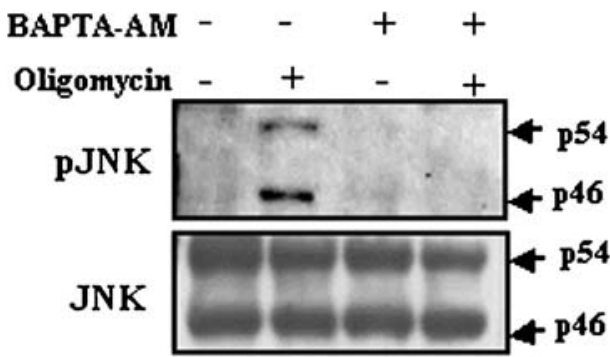

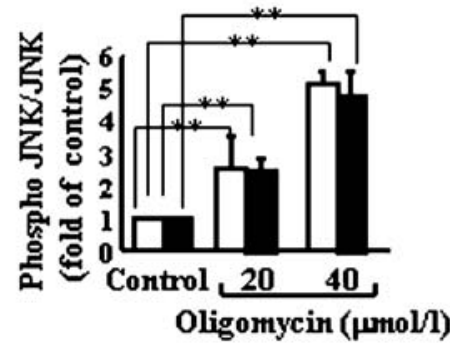
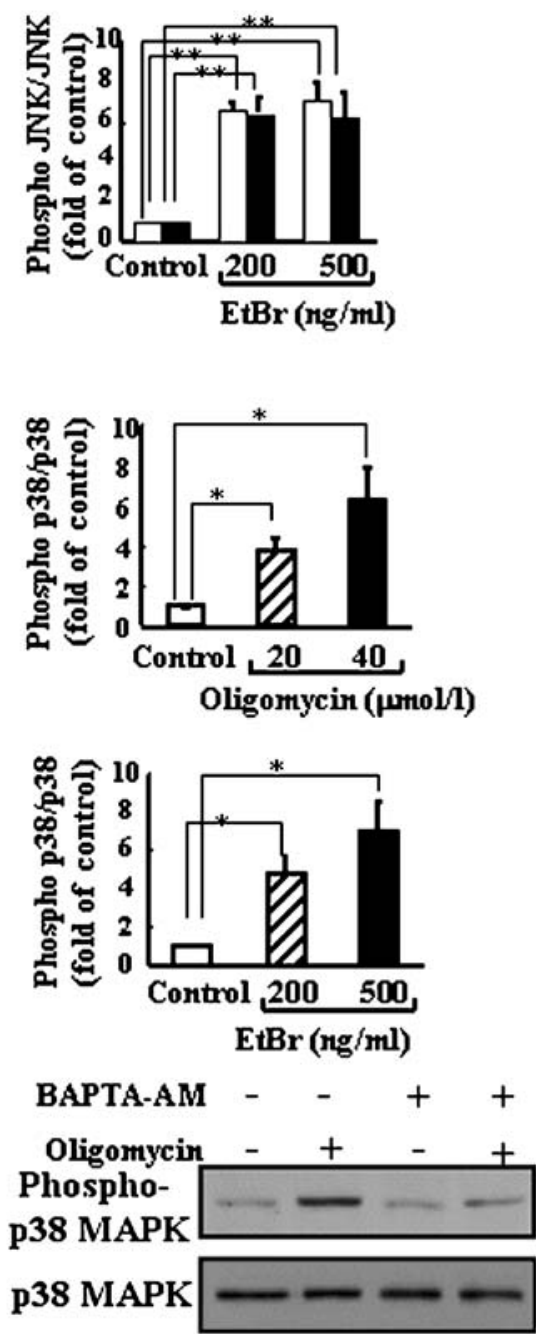
and p38 MAPK basal activity produced by mitochondrial dysfunction, which implies that elevated cellular free $\mathrm{Ca}^{2+}$ is responsible for the aberrant activation of both protein kinases in $\mathrm{C} 2 \mathrm{C} 12$ cells with dysfunctional mitochondria (Fig. 7b).

a

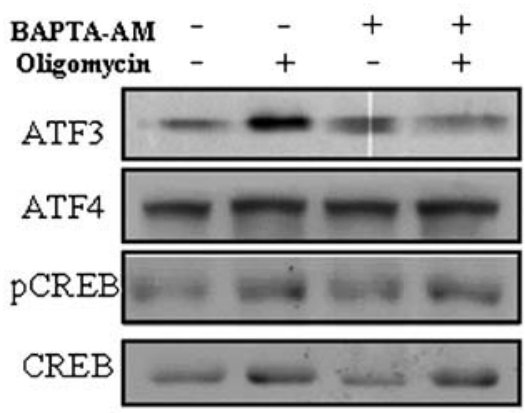

b

ATF3 induced by mitochondrial dysfunction plays an important role in transcriptional repression of Irs 1

In an effort to elucidate the mechanisms responsible for the repression of IRS1 production by mitochondrial stress in C2C12 myotube cells, we next examined transcription factors activated by mitochondrial dysfunction and regulated by $\mathrm{Ca}^{2+}$, JNK or p38 MAPK. As shown in Fig. 8a and $\mathrm{b}$, production of ATF4 was unaffected by oligomycin,

$\begin{array}{lllll}\text { SP600125 } & - & - & + & + \\ \text { Oligomycin } & - & + & - & +\end{array}$

ATF3

ATF4

PCREB

CREB

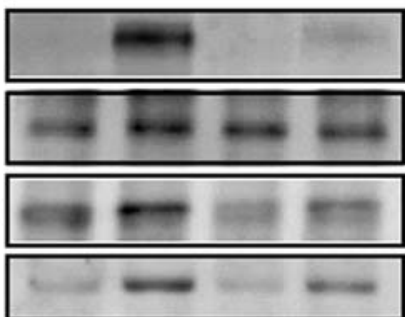

(CCAGCTG)

c
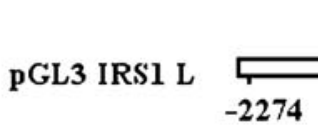

(TGACGTCA)

$-1327$
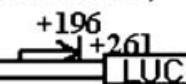

pGL3 IRS1 S

d

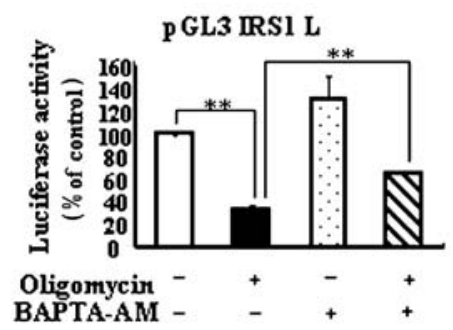

$\mathbf{e}$

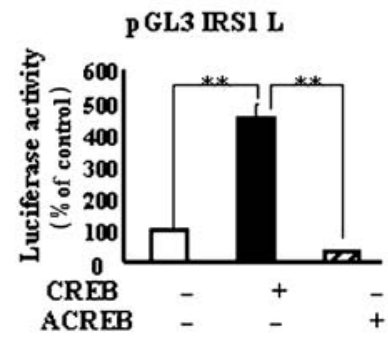

f

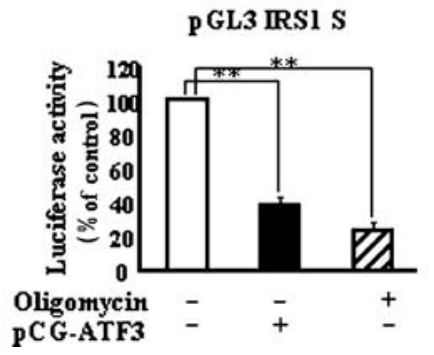

Fig. 8 ATF3 is responsible for repression of IRS1 production by mitochondrial dysfunction. a, b Effects of mitochondrial dysfunction on transcription factors. Whole-cell lysates were obtained from cells as indicated, and the production pattern of various transcription factors was investigated by Western blot analysis with specific antibodies to ATF3, ATF4, CREB and phospho-CREB. c Schematic representation of the Irs 1 gene promoter (pGL3 IRS1 L) and deletion construct (pGL3 IRS1 S) from which -2274 to -191 had been removed. Arrows indicate the transcription start site. The relative positions of the putative ATF3 binding sites are indicated $(-1327,+196)$. d Recovery of Irs 1 promoter activity by BAPTA-
AM and ability of ATF3 to inhibit the Irs 1 promoter activity. $\mathrm{C} 2 \mathrm{C} 12$ cells were transiently transfected with pGL3 IRS1 L ( -2274 to $+261)$ and treated with oligomycin (40 $\mu \mathrm{mol} / \mathrm{l})$, BAPTA-AM $(20 \mu \mathrm{mol} / \mathrm{l})$ or Atf3 expression vector as indicated. e Effects of CREB on Irs 1 gene promoter. Vectors encoding CREB or ACREB (1 $\mu \mathrm{g}$ per well) were cotransfected with pGL3 IRS1 L. f Effects of oligomycin and Atf3 expression vector on pGL3 IRS1 S promoter activity. Oligomycin was added for the final $24 \mathrm{~h}$. Atf3 was cotransfected as described in Materials and methods. All values are means \pm SEM from five independent experiments. $* * p<0.001$ for pairwise comparisons (ANOVA: $\mathbf{d} p<0.0019 ; \mathbf{e} p=0.0005 ; \mathbf{f} p=0.0001$ ) 
whereas the production of both ATF3 and CREB was highly elevated in oligomycin-treated $\mathrm{C} 2 \mathrm{C} 12$ cells; this elevation was diminished by pretreatment with BAPTAAM or JNK inhibitor. As ATF3 is a stress-inducible transcriptional repressor [23], we postulated that ATF3 is a candidate factor associated with decreased $\operatorname{Irs} 1$ expression by mitochondrial dysfunction in $\mathrm{C} 2 \mathrm{C} 12$ myotube cells. We constructed two different luciferase reporter plasmids containing the murine Irs 1 promoter, IRS1 L and IRS1 S, and investigated mitochondrial stress-mediated promoter activity in $\mathrm{C} 2 \mathrm{C} 12$ myotubes. Using TESS, a web-based tool (available from http://www.cbil.upenn.edu/cgi-bin/ tess/tess, last accessed in April 2006) to identify transcription factor binding sites, putative ATF3 DNA binding sites at $-1,327$ and +196 in the Irs 1 promoter region were proposed (Fig. 8c). First, we tested whether the reporter constructs behave as whole IRS1 proteins. As shown in Fig. 8d, consistent with decreased Irs 1 mRNA in C2C12 cells with dysfunctional mitochondria, the promoter activity of IRS1 L decreased three- to four-fold in oligomycintreated cells compared with control $\mathrm{C} 2 \mathrm{C} 12$ cells; this decrease was almost completely restored by BAPTA-AM pretreatment. To demonstrate that ATF3 confers transcriptional repression of Irs 1 induced by mitochondrial stress, we cotransfected an Atf3 expression plasmid with Irs 1 reporter constructs into $\mathrm{C} 2 \mathrm{C} 12$ myotube cells. Results show that expression of Atf3 significantly repressed transcription of the Irs 1 promoter (Fig. 8d), consistent with previous results from oligomycin-mediated repression of the Irs 1 promoter. However, increased CREB activity that was also induced by mitochondrial dysfunction further enhanced Irs 1 promoter activity (Fig. 8e), indicating that CREB is not responsible for the repression of Irs 1 . To determine where ATF3 works on the Irs 1 promoter, we transfected IRS1 S with the Atf3 expression plasmid or treated the cells with oligomycin. As shown in Fig. 8f, both Atf3 transfection and oligomycin treatment repressed promoter activity by more than three- to four-fold, suggesting that the site within 191 bases from the transcription site could mediate repression of Irs 1 by mitochondrial dysfunction. We postulate a mechanism of mitochondrial stress on the production of IRS1 in C2C12 myotube cells, whereby elevated cytosolic free $\mathrm{Ca}^{2+}$ and the subsequent activation of JNK and p38 MAPK induce ATF3 production, which in turn represses IRS1.

\section{Discussion}

Mitochondrial dysfunction contributes to several human diseases, such as obesity, hyperlipidaemia and type 2 diabetes. In this study, we correlated mitochondrial dysfunction and the development of insulin resistance, and we also characterised retrograde signalling using two different $\mathrm{C} 2 \mathrm{C} 12$ cell models of mitochondrial dysfunction. The mitochondrial dysfunctions observed in $\mathrm{C} 2 \mathrm{C} 12$ cells reveal marked decreases in IRS1 and SLC2A4 production (Fig. 2). Furthermore, mitochondrial dysfunction also increases the serine phosphorylation of IRS1 at critical sites (e.g. Ser307 or Ser636/639) and attenuates insulin signalling (Fig. 3). Therefore, basal and insulin-stimulated SLC2A4 translocation and glucose uptake decreased significantly in $\mathrm{C} 2 \mathrm{C} 12$ cells with dysfunctional mitochondria, suggesting that mitochondrial dysfunction can develop into insulin resistance in $\mathrm{C} 2 \mathrm{C} 12$ myotube cells (Fig. 5). In humans, diminished SLC2A4 and IRS1 protein levels can predict the development of type 2 diabetes [38]. Moreover, low levels of IRS1 have been reported in 30\% of subjects at high risk of type 2 diabetes, such as first-degree relatives of type 2 diabetics and obese subjects [29, 38], suggesting that dysregulation of the production of these proteins may be an early step towards the development of type 2 diabetes.

Here, we propose possible molecular mechanisms for how mitochondrial dysfunction causes reductions in IRS1 and insulin resistance, which influences numerous cellular and organismic activities under normal and pathophysiological conditions. In cells with functionally inactivated mitochondria, elevated steady-state cytosolic free $\mathrm{Ca}^{2+}$ and the subsequent activation of JNK and p38 MAPK were responsible for downregulating IRS1 and SLC2A4 (Figs. 6 and 7). The mitochondrion is a known major $\mathrm{Ca}^{2+}$ storage organelle, and important mechanisms for mitochondrial $\mathrm{Ca}^{2+}$ regulation are achieved primarily via the mitochondrial $\mathrm{Ca}^{2+}$ uniporters, whereby $\mathrm{Ca}^{2+}$ is taken up by means of $\Delta \Psi \mathrm{m}$. Therefore, we believe that disruption of $\Delta \Psi \mathrm{m}$ by metabolic and genetic stress in $\mathrm{C} 2 \mathrm{C} 12$ cells impairs $\mathrm{Ca}^{2+}$ uptake, thereby elevating cytosolic free $\mathrm{Ca}^{2+}$. Additionally, the upregulation of genes involved in $\mathrm{Ca}^{2+}$ transport and storage, such as ryanodine receptor I or II, by mitochondrial stress $[19,20]$ may also be involved in elevating cytosolic free $\mathrm{Ca}^{2+}$. Because it has been demonstrated that $\mathrm{Ca}^{2+}$ activates JNK and p38 MAPK [39-41], and we have shown that activation of JNK and p38 MAPK is dependent on $\mathrm{Ca}^{2+}$, the elevation of intracellular $\mathrm{Ca}^{2+}$ induced by mitochondrial dysfunction may trigger the subsequent activation of JNK and p38 MAPK. Actually, a similar pattern of retrograde signalling has been reported whereby respiratory deficiency and its associated increase in cytosolic free $\mathrm{Ca}^{2+}$ activates $\mathrm{Ca}^{2+}$-responsive calcineurin and CaMKIV, which in turn activate their respective transcription factors $[19,22]$.

In an effort to determine which transcription factors function in IRS1 downregulation downstream of $\mathrm{Ca}^{2+}$, JNK or p38 MAPK activation, we found that ATF3 represses IRS1 in a $\mathrm{Ca}^{2+}$ - or JNK-dependent manner (Fig. 8). In fact, expression of Atf 3 in the liver represses the expression of genes encoding gluconeogenic enzymes [42], and the expression of Atf 3 in the pancreas leads to reduced numbers of hormone-producing cells [25]. Although the exact binding sites for ATF3 on the Irs 1 promoter remain unverified, as we have shown in Fig. 8f, the region within 191 bases from the transcription site may be responsible for repression of Irs 1 by mitochondrial dysfunction. However, the biological significance of this and the precise mechanism of ATF 3 regulation by $\mathrm{Ca}^{2+}$ and JNK remains to be elucidated. 
Another possible explanation for how mitochondrial dysfunction induces insulin resistance in vivo comes from reports by Petersen et al. [12, 33]. They demonstrated that insulin resistance in the elderly is related to increases in intramyocellular fatty acid metabolites that may be a result of an age-associated reduction in mitochondrial oxidation and phosphorylation. Hence, dysregulation in intracellular fatty acid metabolism associated with mitochondrial dysfunction may play a critical role in the development of insulin resistance. Coincidentally, we also observed abnormal triglyceride accumulation in $\mathrm{C} 2 \mathrm{C} 12$ cells with dysfunctional mitochondria (Fig. 4), which might also contribute to impairment of insulin signalling leading to insulin resistance, in agreement with a previous report [2].

Recently, Park et al. [43] showed that reductions in Irs 1 expression and insulin-stimulated phosphorylation of IRS1 and Akt2/protein kinase B are associated with insulin resistance in L6 Glut4myc myocytes, where $95 \%$ of mtDNA was depleted by EtBr treatment. They showed no discernible changes in total SLC2A4, whereas we observed reduced SLC2A4 production in oligomycin- or EtBr-treated $\mathrm{C} 2 \mathrm{C} 12$ cells. The different cells used in the experiments may explain this discrepancy. While we employed $\mathrm{C} 2 \mathrm{C} 12$ cells, they used L6Glut4myc cells in which Slc2a4 was highly expressed using enhancers not dependent on intracellular signalling, and consequently total SLC2A4 may be unaffected by mitochondrial stress despite influencing endogenous SLC2A4 production. Furthermore, our investigation found that induction of insulin resistance occurs in dysfunctional mitochondrial C2C12 myotube cells without drastic genetic defects in mtDNA, as produced by Park et al. Therefore, subtle mtDNA defects leading to mitochondrial dysfunction can be sufficient to trigger the pathogenesis of insulin resistance and type 2 diabetes.

In conclusion, we demonstrate here that mitochondrial dysfunction causes inactivation of IRS1 and a drastic reduction in IRS1 and SLC2A4 production in a $\mathrm{Ca}^{2+}$ dependent manner, thereby inducing aberrant insulin signalling and glucose utilisation, as observed in type 2 diabetes. Additionally, we observed that JNK and p38 MAPK function as potential candidates for modulating the loss of IRS1 and SLC2A4 production, and that ATF3 is involved in repressing Irs 1 gene expression. We characterised one mechanism underlying the molecular sensing of genetic and environmentally induced stress by mitochondria and the resulting inhibition of insulin signalling, ultimately leading to insulin resistance.

Acknowledgements This work was supported by research grants from the Korean National Institutes of Health (347-6111-211-207). J. H. Lim and J. I. Lee contributed equally to this work. We would like to acknowledge J. E. Pessin (Medical Center at Stony Brook) for his generous gift of pSLC2A4-GFP, C. R. Kahn (Harvard Medical School) for pBlue-IRS1, T. Hai (Indiana University School of Medicine) for pCG-ATF3, and S. Sarsfield (Johns Hopkins University School of Medicine) for pcDNA-CREB and pcDNA-ACREB.

\section{References}

1. Duchen MR (2004) Roles of mitochondria in health and disease. Diabetes 53(Suppl 1):S96-S102

2. Lowell BB, Shulman GI (2005) Mitochondrial dysfunction and type 2 diabetes. Science 307:384-387

3. Parish R, Petersen KF (2005) Mitochondrial dysfunction and type 2 diabetes. Curr Diab Rep 5:177-183

4. Janssen GM, Maassen JA, van Den Ouweland JM (1999) The diabetes-associated 3243 mutation in the mitochondrial tRNA (Leu(UUR)) gene causes severe mitochondrial dysfunction without a strong decrease in protein synthesis rate. J Biol Chem 274:29744-29748

5. Petersen KF, Shulman GI (2002) Pathogenesis of skeletal muscle insulin resistance in type 2 diabetes mellitus. Am J Cardiol 90:11G-18G

6. Read CY, Calnan RJ (2000) Mitochondrial disease: beyond etiology unknown. J Pediatr Nurs 15:232-241

7. Wilson FH, Hariri A, Farhi A et al (2004) A cluster of metabolic defects caused by mutation in a mitochondrial tRNA. Science 306:1190-1194

8. van den Ouweland JM, Maechler P, Wollheim CB, Attardi G, Maassen JA (1999) Functional and morphological abnormalities of mitochondria harbouring the tRNA(Leu)(UUR) mutation in mitochondrial DNA derived from patients with maternally inherited diabetes and deafness (MIDD) and progressive kidney disease. Diabetologia 42:485-492

9. Olsson C, Johnsen E, Nilsson M, Wilander E, Syvanen AC, Lagerstrom-Fermer M (2001) The level of the mitochondrial mutation A3243G decreases upon ageing in epithelial cells from individuals with diabetes and deafness. Eur J Hum Genet 9:917-921

10. Olsson C, Zethelius B, Lagerstrom-Fermer M, Asplund J, Berne C, Landegren U (1998) Level of heteroplasmy for the mitochondrial mutation $\mathrm{A} 3243 \mathrm{G}$ correlates with age at onset of diabetes and deafness. Hum Mutat 12:52-58

11. Maassen JA (2002) Mitochondrial diabetes: pathophysiology, clinical presentation, and genetic analysis. Am J Med Genet 115:66-70

12. Petersen KF, Dufour S, Befroy D, Garcia R, Shulman GI (2004) Impaired mitochondrial activity in the insulin-resistant offspring of patients with type 2 diabetes. N Engl J Med 350:664671

13. Epstein CB, Waddle JA, Hale W et al (2001) Genome-wide responses to mitochondrial dysfunction. Mol Biol Cell 12:297308

14. Butow RA, Avadhani NG (2004) Mitochondrial signaling: the retrograde response. Mol Cell 14:1-15

15. Liao XS, Small WC, Srere PA, Butow RA (1991) Intramitochondrial functions regulate nonmitochondrial citrate synthase (CIT2) expression in Saccharomyces cerevisiae. Mol Cell Biol $11: 38-46$

16. Liao X, Butow RA (1993) RTG1 and RTG2: two yeast genes required for a novel path of communication from mitochondria to the nucleus. Cell 72:61-71

17. Komeili A, Wedaman KP, O’Shea EK, Powers T (2000) Mechanism of metabolic control. Target of rapamycin signaling links nitrogen quality to the activity of the Rtg1 and Rtg3 transcription factors. J Cell Biol 151:863-878

18. Sekito T, Thornton J, Butow RA (2000) Mitochondria-tonuclear signaling is regulated by the subcellular localization of the transcription factors Rtglp and Rtg3p. Mol Biol Cell 11:2103-2115

19. Biswas G, Adebanjo OA, Freedman BD et al (1999) Retrograde $\mathrm{Ca}^{2+}$ signaling in $\mathrm{C} 2 \mathrm{C} 12$ skeletal myocytes in response to mitochondrial genetic and metabolic stress: a novel mode of inter-organelle crosstalk. EMBO J 18:522-533

20. Amuthan G, Biswas G, Ananadatheerthavarada HK, Vijayasarathy C, Shephard HM, Avadhani NG (2002) Mitochondrial stressinduced calcium signaling, phenotypic changes and invasive behavior in human lung carcinoma A549 cells. Oncogene 21:7839-7849 
21. De Cesare D, Fimia GM, Sassone-Corsi P (1999) Signaling routes to CREM and CREB: plasticity in transcriptional activation. Trends Biochem Sci 24:281-285

22. Arnould T, Vankoningsloo S, Renard P et al (2002) CREB activation induced by mitochondrial dysfunction is a new signaling pathway that impairs cell proliferation. EMBO J 21:53-63

23. Hai T, Wolfgang CD, Marsee DK, Allen AE, Sivaprasad U (1999) ATF3 and stress responses. Gene Expr 7:321-335

24. Wright DE, Ryals JM, McCarson KE, Christianson JA (2004) Diabetes-induced expression of activating transcription factor 3 in mouse primary sensory neurons. J Peripher Nerv Syst 9:242254

25. Hartman MG, Lu D, Kim ML et al (2004) Role for activating transcription factor 3 in stress-induced beta-cell apoptosis. Mol Cell Biol 24:5721-5732

26. Allen-Jennings AE, Hartman MG, Kociba GJ, Hai T (2001) The roles of ATF3 in glucose homeostasis. A transgenic mouse model with liver dysfunction and defects in endocrine pancreas. J Biol Chem 276:29507-29514

27. Amuthan G, Biswas G, Zhang SY, Klein-Szanto A, Vijayasarathy C, Avadhani NG (2001) Mitochondria-to-nucleus stress signaling induces phenotypic changes, tumor progression and cell invasion. EMBO J 20:1910-1920

28. Pessin JE, Saltiel AR (2000) Signaling pathways in insulin action: molecular targets of insulin resistance. J Clin Invest 106:165-169

29. Smith U (2002) Impaired ('diabetic') insulin signaling and action occur in fat cells long before glucose intolerance-is insulin resistance initiated in the adipose tissue? Int $\mathrm{J}$ Obes Relat Metab Disord 26:897-904

30. Zick Y (2004) Uncoupling insulin signalling by serine/threonine phosphorylation: a molecular basis for insulin resistance. Biochem Soc Trans 32:812-816

31. Zick Y (2001) Insulin resistance: a phosphorylation-based uncoupling of insulin signaling. Trends Cell Biol 11:437-441

32. Zick Y (2005) Ser/Thr phosphorylation of IRS proteins: a molecular basis for insulin resistance. Sci STKE 2005:e4
33. Petersen KF, Befroy D, Dufour S et al (2003) Mitochondrial dysfunction in the elderly: possible role in insulin resistance. Science 300:1140-1142

34. Vankoningsloo S, Piens M, Lecocq C et al (2005) Mitochondrial dysfunction induces triglyceride accumulation in 3T3-L1 cells: role of fatty acid beta-oxidation and glucose. J Lipid Res 46:1133-1149

35. Roden M (2005) Muscle triglycerides and mitochondrial function: possible mechanisms for the development of type 2 diabetes. Int J Obes 29(Suppl 2):S111-S115

36. Zhao Y, Zhang L, Longo LD (2005) PKC-induced ERK1/2 interactions and downstream effectors in ovine cerebral arteries. Am J Physiol Regul Integr Comp Physiol 289:R164-R171

37. Maas JW Jr, Vogt SK, Chan GC, Pineda VV, Storm DR, Muglia LJ (2005) Calcium-stimulated adenylyl cyclases are critical modulators of neuronal ethanol sensitivity. J Neurosci 25:41184126

38. Carvalho E, Jansson PA, Axelsen M et al (1999) Low cellular IRS 1 gene and protein expression predict insulin resistance and NIDDM. FASEB J 13:2173-2178

39. Kim MS, Lim WK, Park RK et al (2005) Involvement of mitogen-activated protein kinase and NF- $\mathrm{KB}$ activation in $\mathrm{Ca}^{2+}$ induced IL- 8 production in human mast cells. Cytokine 32:226-233

40. Allaman-Pillet N, Storling J, Oberson A et al (2003) Calciumand proteasome-dependent degradation of the JNK scaffold protein islet-brain 1. J Biol Chem 278:48720-48726

41. Storling J, Zaitsev SV, Kapelioush IL et al (2005) Calcium has a permissive role in interleukin-1 beta-induced c-Jun N-terminal kinase activation in insulin-secreting cells. Endocrinology 146:3026-3036

42. Allen-Jennings AE, Hartman MG, Kociba GJ, Hai T (2002) The roles of ATF3 in liver dysfunction and the regulation of phosphoenolpyruvate carboxykinase gene expression. J Biol Chem 277:20020-20025

43. Park SY, Choi GH, Choi HI, Ryu J, Jung CY, Lee W (2005) Depletion of mitochondrial DNA causes impaired glucose utilization and insulin resistance in L6 GLUT4myc myocytes. J Biol Chem 280:9855-9864 